\title{
Patterns of non-communicable disease and injury risk factors in Kenyan adult population: a cluster analysis
}

\author{
Tilahun Nigatu Haregu ${ }^{1,4+}$, Frederick M Wekesah ${ }^{1,2^{*}+}$, Shukri F Mohamed ${ }^{1,3}$, Martin K Mutua', Gershim Asiki \\ and Catherine Kyobutungi ${ }^{1}$
}

\begin{abstract}
Background: Non-communicable diseases and unintentional injuries are emerging public health problems in subSaharan Africa. These threats have multiple risk factors with complex interactions. Though some studies have explored the magnitude and distribution of those risk factors in many populations in Kenya, an exploration of segmentation of population at a national level by risk profile, which is crucial for a differentiated approach, is currently lacking. The aim of this study was to examine patterns of non-communicable disease and injury risk through the identification of clusters and investigation of correlates of those clusters among Kenyan adult population.

Methods: We used data from the 2015 STEPs survey of non-communicable disease risk factors conducted among 4484 adults aged between 18 and 69 years in Kenya. A total of 12 risk factors for NCDs and 9 factors for injury were used as clustering variables. A K-medians Cluster Analysis was applied. We used matching as the measure of the similarity/dissimilarity among the clustering variables. While clusters were described using the risk factors, the predictors of the clustering were investigated using multinomial logistic regression.

Results: We have identified five clusters for NCDs and four clusters for injury based on the risk profile of the population. The NCD risk clusters were labelled as cluster hypertensives, harmful users, the hopefuls, the obese, and the fat lovers. The injury risk clusters were labelled as helmet users, jaywalkers, the defiant and the compliant. Among the possible predictors of clustering, age, gender, education and wealth index came out as strong predictors of the cluster variables.

Conclusion: This cluster analysis has identified important clusters of adult Kenyan population for non-communicable disease and injury risk profiles. Risk reduction interventions could consider these clusters as potential target in the development and segmentation of a differentiated approach.
\end{abstract}

Keywords: Non-communicable disease, Injury, Risk factor, Cluster analysis, STEPS, Kenya

\section{Background}

Non-communicable diseases (NCDs) cause more deaths globally than all other causes combined together $[1,2]$. In 2012, about 38 million people died from NCDs, and the number of deaths is projected to reach 52 million by the year 2030 [1-5]. Cardiovascular diseases (CVDs), cancers, chronic respiratory diseases and diabetes comprise $80 \%$ of

\footnotetext{
* Correspondence: fwekesah@aphrc.org

'African Population and Health Research Center (APHRC), 2nd Floor APHRC

Campus, Manga Close Off Kirawa Road, P.O. Box 10787, Kitisuru, Nairobi GPO 00100, Kenya

${ }^{2}$ Julius Global Health, Julius Center for Health Sciences and Primary Care,

University Medical Center, Utrecht University, Utrecht, The Netherlands

Full list of author information is available at the end of the article
}

NCDs. The shift in the global burden of disease from communicable diseases to NCDs is attributed to population growth and the increased average age of the world's population, combined with the decreasing age-, sex- and cause-specific death rates [6].

NCDs are caused by multiple risk factors which interact in a complex way [7]. Many of the risk factors for NCDs are related to lifestyle and are therefore modifiable. These modifiable risk factors include physical inactivity, low fruit and vegetable intake, unhealthy diet and high cholesterol intake. Physiological risk factors for NCDs include overweight and obesity $[7,8]$.

(c) The Author(s). 2018 Open Access This article is distributed under the terms of the Creative Commons Attribution 4.0 International License (http://creativecommons.org/licenses/by/4.0/), which permits unrestricted use, distribution, and 
Achieving the $25 * 25$ target, which is the reduction of premature mortality from four main NCDs-cardiovascular diseases, chronic respiratory diseases, cancers, and diabetes-by $25 \%$ from 2010 levels by 2025 [7] will very much depend on achieving the risk factor target on the key risk factors for NCDs (tobacco and alcohol use, salt intake, obesity, and raised blood pressure and glucose) [7].

As the risk factors for many of the common NCDs are shared, the likelhood of their co-occurrence is high. Thus, studies of single risk factors or prevalence of individual risk factors will miss the complex interaction among the risk factors. For a better understanding of risk profiles of a population, the whole set of risk factors should be considered. Hence, there is a need for approaches that consider common risk factors together to describe risk profile of the population.

This study sought to investigate patterns of NCD risk factors, hence profiles of the Kenyan population based on the clustering of these risk factors. Different segments of the population experience, or are exposed to different risk factors and therefore have different risk profiles, and will require targeted approaches and interventions in mitigating these risk factors for the prevention of NCDs.

\section{Methods}

The Kenya 2015 STEPS survey was a cross-sectional household survey that was carried out in Kenya from April to June 2015,targeting individuals aged between 18 and 69 years. The survey used the fifth national sample surveys and evaluation programme (NASSEP V) sampling frame from the Kenya National Bureau of Statistics, developed using the enumeration areas generated from the 2009 Kenya population and Housing census. The sample size was determined to be 6000 to allow for national estimates as per sex and residence (rural or urban).

A three stage cluster sample design was used. In the first stage, 200 clusters (100 urban and 100 rural) were selected. In the second stage, a uniform sample of 30 households from the listed households in each cluster, while in the third stage, one individual was randomly selected from all eligible listed household members.

\section{Data collection}

Socio-demographic and behavioral information was collected in step 1, physical measurements such as height, weight and blood pressure were collected in step 2 while biochemical measurements for blood glucose and cholesterol were taken in step 3 with respondents in a fasting state.

The survey focussed on the four main behavioural risk factors of NCDs: tobacco use, harmful alcohol consumption, unhealthy diet and lack of physical activity; and the four key physiological risk factors for NCDs:overweight and obesity, raised blood pressure, raised blood lipids and raised blood glucose. The survey questionnaire was adapted from the WHO STEPS instrument [9], with information being gathered in three sequential steps. Step one involved asking questions on demographic information such as age, sex, marital status, education and occupation, housing and social amenities as well as dietary history on salt, sugar, fat, fruits and vegetable intakes. Data collection was through a personal digital assistant (PDA) loaded with eSTEPS software provided by WHO.

Twenty multidisciplinary teams (supervisor, two research assistants, a clinician and laboratory technologist) were involved in data collection after undergoing a six day training on survey background, sampling method, questioning techniques, PDA use and ethical procedures.

\section{Key variables}

Twelve traditional non-communicable disease risk factors and nine risk factors for injuries were used in our analysis. These measures were both self-reported and objectively measured. The inclusion of these risk factors was based on availability of complete data for the study population. The cut-off points for these variables were based on international recommendations [10-13].

\section{Risk variables for NCDs and injury $N C D$ risk variables}

Inadequate fruit/vegetable intake, high sugar intake, insufficient physical activity, harmful alcohol use, tobacco use, excessive sitting time, general obesity, central obesity, high blood sugar, high salt consumption, high fat intake, and increased blood pressure.

\section{Injury risk factors}

Didn't use seatbelt, didn't use helmet, involved in traffic crash, had accidental injury, inappropriate road crossing, driving under influence of alcohol, was a passenger of drunk driver, involved in violence, and substance use/e.g. khat.

\section{Data management and analysis}

We used Stata 14.1 (Stata Corporation, College Station, TX) to analyse the data. Analysis was restricted to individuals with complete data on the key analytic variables listed above. Those with missing values were excluded from the analysis.

\section{Cluster identification}

For both categories of risk factors, the variables were recoded as 0 (low risk) and 1 (higher risk). Given the nature of the data, binary data, we used K-median cluster analysis approach. We used matching as a measure of distance of proximity. We used the scree plot to determine the ideal number of clusters. 


\section{Cluster characterization}

The distribution of the risk factors across the clusters was examined to characterize the clusters based on the risk profile. Clusters were named based on their unique dominant risk profiles. The background characteristics of participants in each cluster were also summarized using proportions and the associations were tested using chi-square statistics.

\section{Predictors of cluster distribution}

Predictors of the cluster distributions were examined using logistic regression models. The background characteristics included in the model were age, gender, education, employment, residence, wealth index, and marital status. Results of this are presented in tables.

\section{Ethical considerations}

Written informed consent was obtained from every participant. Personal identifiers were delinked from the data by coding and the consent forms that contained personal identifiers were stored separately from the coded data. The data collection team was trained on ethical procedures and appropriate data collection techniques.

\section{Results}

\section{Characteristics of study population}

In total 4484 adults aged between 18 and 69 years were included in the study with nearly an equal representation women and men (51.3\% versus $48.8 \%)$, and about half were young people aged 18-29 years, 65.5\% married, $61.9 \%$ were rural residents, $12.6 \%$ had no formal education, $18.9 \%$ were classified as poorest and $23.4 \%$ richest and up to $40.1 \%$ were unemployed (Table 1 ).

\section{Cluster analysis of NCD risk factors}

Using the 12 risk variables, the optimum number of clusters was found to be five. The distribution of the risk variables across the clusters is shown in Table 2 below.

As displayed in the Table 2, participants in cluster 1 were all with hypertension. We labelled this cluster as "hypertensives." Participants in cluster 2 had high rates of harmful use of alcohol, tobacco use and salt consumption as compared to the rest of the clusters. We labelled this cluster as "harmful users." Participants in the fourth cluster had highest rates of general and abdominal obesity. These were labelled as "the obese." Those in the fifth cluster had the highest rate of high fat consumption and thus were labelled as "fat lovers." Participants in the third cluster have no extreme risk and were labelled as the "hopefuls." Inadequate fruit and vegetable consumption was universal across all five clusters. Similarly, physical inactivity was not common in all clusters.
Table 1 Socio-demographic characteristics

\begin{tabular}{|c|c|c|}
\hline Characteristics & Number & Percent \\
\hline \multicolumn{3}{|l|}{ Sex } \\
\hline Female & 2298 & 51.3 \\
\hline Male & 2186 & 48.8 \\
\hline \multicolumn{3}{|l|}{ Age groups } \\
\hline $18-29$ & 2062 & 46.0 \\
\hline $30-39$ & 1045 & 23.3 \\
\hline $40-49$ & 695 & 15.5 \\
\hline $50-59$ & 443 & 9.9 \\
\hline $60-69$ & 239 & 5.3 \\
\hline \multicolumn{3}{|l|}{ Marital status } \\
\hline Not married & 1039 & 23.2 \\
\hline Married & 2938 & 65.5 \\
\hline Formerly married & 507 & 11.3 \\
\hline \multicolumn{3}{|l|}{ Residence } \\
\hline Rural & 2776 & 61.9 \\
\hline Urban & 1708 & 38.1 \\
\hline \multicolumn{3}{|l|}{ Education level } \\
\hline No formal education & 563 & 12.6 \\
\hline Primary education & 2043 & 45.6 \\
\hline Secondary and above & 1877 & 41.9 \\
\hline \multicolumn{3}{|l|}{ Household wealth status } \\
\hline Poorest & 848 & 18.9 \\
\hline Second & 937 & 20.9 \\
\hline Middle & 818 & 18.3 \\
\hline Fourth & 832 & 18.6 \\
\hline Richest & 1049 & 23.4 \\
\hline \multicolumn{3}{|l|}{ Occupation } \\
\hline Unemployed & 1799 & 40.1 \\
\hline Employed & 2685 & 59.9 \\
\hline
\end{tabular}

\section{Profile of the NCD risk clusters}

As compared to the other clusters, the hopefuls and fat lovers are younger. The mean (SD) ages were 33.9 (12.3) and 34.6 (12.4) years respectively. The mean ages for hypertensives, harmful users and the obese were 43.2 (14.8), 40.9 (12.8), and 41.2 (12.6) years, respectively. As to gender, majority of the harmful users $(87 \%)$ were male. On the other hand, more than three quarters (78\%) of the obese were female. Majority of the obese were urban residents while the fat lovers were rural residents. The hopefuls are equally distributed between rural and urban areas. A little more than half of the hypertensives and harmful users lived in rural areas. Details are shown in Table 3.

The proportion of people in the hopeful and obese groups increased with educational status. The harmful users and the obese were dominated by the unemployed 
Table 2 Distribution of specific risk factors by clusters

\begin{tabular}{|c|c|c|c|c|c|c|c|}
\hline SN & NCD Risk Variables & Cluster 1 & Cluster 2 & Cluster 3 & Cluster 4 & Cluster 5 & Total \\
\hline 1 & Inadequate Fruit/vegetables & 99.4 & 100 & 99.7 & 99.8 & 99.8 & 99.8 \\
\hline 2 & High sugar intake & 12.2 & 11.8 & 11.5 & 16.9 & 17.0 & 13.9 \\
\hline 3 & Insufficient physical activity & 7.8 & 4.8 & 9.2 & 11.9 & 4.7 & 8.8 \\
\hline 4 & Excessive alcohol use & 10.6 & 98.5 & 6.6 & 5.7 & 0.0 & 11.8 \\
\hline 5 & Tobacco use & 9.1 & 65.8 & 8.2 & 3.3 & 12.6 & 12.3 \\
\hline 6 & Excessive sitting time & 25.3 & 20.6 & 24.8 & 23.9 & 15.1 & 22.1 \\
\hline 7 & General obesity & 9.5 & 5.5 & 8.4 & 99.3 & 6.5 & 31.4 \\
\hline 8 & Central obesity & 25.1 & 10.7 & 14.5 & 99.2 & 11.1 & 36.8 \\
\hline 9 & High blood sugar & 13.5 & 9.9 & 9.1 & 15.7 & 6.6 & 10.9 \\
\hline 10 & High salt consumption & 12.9 & 34.6 & 21.0 & 18.5 & 18.7 & 19.6 \\
\hline 11 & High fat intake & 38.1 & 80.1 & 0.0 & 29.0 & 100 & 41.5 \\
\hline \multirow[t]{4}{*}{12} & Increased blood pressure & 100 & 27.9 & 0.0 & 42.0 & 4.3 & 27.6 \\
\hline & Cluster size & 549 & 272 & 1196 & 1024 & 922 & 3963 \\
\hline & $\%$ of total & 14.0 & 7.0 & 30.0 & 26.0 & 23.0 & 100 \\
\hline & Suggested cluster name & Hypertensives & Harmful users & Hopefuls & The obese & Fat lovers & \\
\hline
\end{tabular}

$N C D=$ Non-Communicable diseases; The clusters are groups of study participants with similar pattern of NCD risk factors; All the values for risk factors are percentages.

The italicised proportions characterise the cluster

(70\% and 66\%, respectively). Analysis of wealth index among the clusters showed that the proportion of participants in the obese cluster increased linearly with wealth index.

\section{Predictors of the NCD clusters}

For the NCD risk clusters, in multivariate analysis, higher age was found to be the predictor for the hypertensives. Being male was the strongest factor associated with belonging to the harmful users' cluster. We also found that wealth was strongly associated with the obese cluster. Age, educational status and wealth index were associated with the hopefuls cluster. Details are shown in Table 4 below.

\section{Cluster analysis of injury risk factors}

Using the same cluster analysis approach for the nine injury risk factors, the optimum number of clusters was found to be four. A total of 3981 participants were included in this cluster analysis. The distribution of the injury risk factors is shown in Table 5 .

While characterizing the clusters by risk factors we found that participants in cluster 1 had considerable use of helmets when they use motorcycle, cycle or scooter. This group was labelled as "Helmet users." Those in the second cluster were known for inappropriate road crossing and are labelled as "jaywalkers." All the participants in the third cluster didn't use seatbelt when they had to. We labelled this group as "the defiant." Lastly, those in the fourth cluster, had remarkable level of seatbelt use and they did appropriate road crossing. We labelled this cluster as "the compliant."

\section{Profile of injury clusters}

The average age decreased modestly as one goes from helmet users to the compliant though the differences were not significant. Education of the participants was found to be an important factor in the profiling of the clusters. We found that the proportion of participants in the compliant cluster increases with their educational level. Close to $60 \%$ of the helmet users had completed at least primary education. On the contrary, about $60 \%$ of the jaywalkers had a similar educational level. While more than $40 \%$ of the seatbelt users and the compliant were on the higher side of wealth index, $46 \%$ of the defiant were in the lower wealth index category. Surprisingly, $44 \%$ of the jaywalkers were also within the higher wealth index categories. Profile of injury clusters is summarized in Table 6.

\section{Predictors of the injury clusters}

In the injury clusters, age, education and wealth were negatively associated with the likelihood of an individual to belong to the defiant group. Educational status was also a predictor of the compliant cluster, but also the jaywalkers' cluster. Richest groups had high level of helmet use as compared to others. Predictors of injury clusters is displayed in Table 7.

\section{Discussion}

The STEPS survey is the first countrywide population based NCD survey in Kenya and has provided important insights into the burden of NCD and injury risk profiles of both rural and urban populations. Cluster analysis 
Table 3 Clusters of NCD risk factors by background variables

\begin{tabular}{|c|c|c|c|c|c|c|c|}
\hline SN & NCD Risk Variables & Hypertensives & Harmful users & Hopefuls & The obese & Fat lovers & $p$-value \\
\hline \multirow[t]{5}{*}{1} & Age & & & & & & \\
\hline & $18-29$ & 23.9 & 19.5 & 43.9 & 20.0 & 40.1 & $<0.001$ \\
\hline & $30-44$ & 29.3 & 43.8 & 36.0 & 42.8 & 39.8 & \\
\hline & $45-59$ & 27.0 & 24.6 & 14.9 & 26.1 & 14.4 & \\
\hline & $60-69$ & 19.9 & 12.1 & 5.3 & 11.1 & 5.6 & \\
\hline \multirow[t]{3}{*}{2} & Sex & & & & & & \\
\hline & Female & 53.7 & 12.9 & 58.8 & 78.1 & 56.3 & $<0.001$ \\
\hline & Male & 46.3 & 87.1 & 41.2 & 21.9 & 43.7 & \\
\hline \multirow[t]{3}{*}{3} & Residence & & & & & & \\
\hline & Rural & 55.9 & 57.0 & 50.1 & 41.4 & 60.0 & $<0.001$ \\
\hline & Urban & 44.1 & 43.0 & 49.9 & 58.6 & 40.0 & \\
\hline \multirow[t]{5}{*}{4} & Education & & & & & & \\
\hline & No schooling & 20.0 & 13.2 & 18.6 & 11.4 & 16.5 & $<0.001$ \\
\hline & Primary incomplete & 21.0 & 35.3 & 24.2 & 20.3 & 29.0 & \\
\hline & Primary complete & 32.6 & 28.3 & 27.8 & 33.4 & 35.1 & \\
\hline & Secondary+ & 26.4 & 23.2 & 29.4 & 34.9 & 19.4 & \\
\hline \multirow[t]{3}{*}{5} & Employment & & & & & & \\
\hline & Employed & 45.9 & 30.2 & 43.1 & 33.7 & 47.2 & $<0.001$ \\
\hline & Unemployed & 54.1 & 69.9 & 56.9 & 66.3 & 52.8 & \\
\hline \multirow[t]{6}{*}{6} & Wealth index & & & & & & \\
\hline & Poorest & 20.0 & 25.7 & 24.5 & 8.1 & 26.6 & $<0.001$ \\
\hline & Second & 23.0 & 24.6 & 18.2 & 12.9 & 27.3 & \\
\hline & Third & 24.4 & 19.9 & 17.1 & 21.2 & 20.0 & \\
\hline & Fourth & 18.4 & 18.0 & 19.2 & 23.7 & 17.7 & \\
\hline & Richest & 14.2 & 11.8 & 20.9 & 34.1 & 8.5 & \\
\hline \multirow[t]{3}{*}{7} & Marital status & & & & & & \\
\hline & Not in Union & 34.2 & 37.5 & 36.2 & 27.1 & 30.4 & $<0.001$ \\
\hline & Union & 65.8 & 62.5 & 63.8 & 72.9 & 69.6 & \\
\hline
\end{tabular}

$N C D=$ Non-communicable diseases; Values in the clusters are percentages

was employed to determine patterns of NCD and injury risks and this segmented the population into five heterogeneous NCD risk clusters and four injury risk clusters. Two of the NCD risk clusters named fat lovers $(23 \%)$ and harmful users (7\%) demonstrated patterns consistent with three known behavioural NCD risk factors- unhealthy diet, tobacco smoking and harmful use of alcohol, and two NCD risk clusters referred to as the obese (26\%) and the hypertensive (14\%) fell in the physiological NCD risk group. One cluster had no extreme NCD risk. However, in all clusters fruit and vegetables consumption was way below the recommended five servings per day and physical inactivity was not common.

These findings are consistent with literature from rural and urban settings in Kenya highlighting that the burden of NCDs is driven by all the known behavioural and physiological NCD risk factors but not physical inactivity
[14-16]. Recent publications from other countries in East Africa have revealed similar findings of dietary habits characterised by poor consumption of fruits and vegetables and a high consumption of fats and carbohydrate amidst adequate physical activity $[17,18]$, a pattern typical of an early phase of nutrition transition [19].

Our study has identified distinct population groups with prevalent NCD risk factors for targeted interventions. It is interesting to note that the smallest NCD risk cluster represents tobacco consumption, harmful alcohol consumption and excessive salt use. The lower frequency of harmful alcohol use and tobacco smoking may be a reflection of the relative success in the development and implementation of policies addressing the WHO "best buy" interventions for NCD prevention. These policies should ideally include measures to reduce common NCD risk factors such as tobacco use, unhealthy diet, physical inactivity 
Table 4 Predictors of NCD risk clusters

\begin{tabular}{|c|c|c|c|c|c|c|c|c|c|c|}
\hline & \multicolumn{2}{|c|}{ Hypertensives } & \multicolumn{2}{|c|}{ Harmful users } & \multicolumn{2}{|c|}{ Hopefuls } & \multicolumn{2}{|c|}{ The obese } & \multicolumn{2}{|c|}{ Fat lovers } \\
\hline & $\mathrm{OR}$ & $(95 \% \mathrm{Cl})$ & $\mathrm{OR}$ & $(95 \% \mathrm{Cl})$ & $\mathrm{OR}$ & $(95 \% \mathrm{Cl})$ & $\mathrm{OR}$ & $(95 \% \mathrm{Cl})$ & $\overline{\mathrm{OR}}$ & $(95 \% \mathrm{Cl})$ \\
\hline \multicolumn{11}{|l|}{ Age } \\
\hline 18-29 years (reference) & 1.00 & & 1.00 & & 1.00 & & 1.00 & & 1.00 & \\
\hline $30-44$ years & 1.11 & $(0.85,1.43)$ & 2.11 & $(1.44,3.07)$ & 0.59 & $(0.50,0.70)$ & 2.76 & $(2.22,3.42)$ & 0.67 & $(0.56,0.81)$ \\
\hline $45-59$ years & 2.09 & $(1.59,2.73)$ & 2.54 & $(1.67,3.88)$ & 0.4 & $(0.32,0.49)$ & 4.37 & $(3.42,5.59)$ & 0.4 & $(0.32,0.51)$ \\
\hline $60-69$ years & 3.62 & $(2.66,4.94)$ & 2.43 & $(1.47,4.01)$ & 0.25 & $(0.18,0.34)$ & 5.25 & $(3.82,7.21)$ & 0.3 & $(0.21,0.42)$ \\
\hline \multicolumn{11}{|l|}{ Sex } \\
\hline Female (reference) & 1.00 & & 1.00 & & 1.00 & & 1.00 & & 1.00 & \\
\hline Male & 1.44 & $(1.18,1.76)$ & 14.3 & $(9.74,21.03)$ & 1.08 & $(0.93,1.25)$ & 0.19 & $(0.15,0.23)$ & 1.37 & $(1.16,1.61)$ \\
\hline \multicolumn{11}{|l|}{ Marital status } \\
\hline Not in union (reference) & 1.00 & & 1.00 & & 1.00 & & 1.00 & & 1.00 & \\
\hline In Union & 0.92 & $(0.74,1.14)$ & 0.51 & $(0.37,0.70)$ & 0.85 & $(0.72,1.00)$ & 1.62 & $(1.33,1.97)$ & 1.1 & $(0.92,1.32)$ \\
\hline \multicolumn{11}{|l|}{ Residence } \\
\hline \multicolumn{11}{|l|}{ Rural (reference) } \\
\hline Urban & 0.94 & $(0.76,1.16)$ & 0.96 & $(0.71,1.31)$ & 1.13 & $(0.96,1.33)$ & 0.99 & $(0.82,1.20)$ & 1.02 & $(0.85,1.22)$ \\
\hline \multicolumn{11}{|l|}{ Education } \\
\hline No schooling (reference) & 1.00 & & 1.00 & & 1.00 & & 1.00 & & 1.00 & \\
\hline Primary incomplete & 0.76 & $(0.56,1.04)$ & 1.43 & $(0.91,2.25)$ & 0.71 & $(0.56,0.90)$ & 1.21 & $(0.90,1.63)$ & 1.13 & $(0.88,1.46)$ \\
\hline Primary complete & 1.08 & $(0.79,1.47)$ & 0.87 & $(0.54,1.40)$ & 0.56 & $(0.44,0.72)$ & 1.48 & $(1.10,1.99)$ & 1.14 & $(0.87,1.48)$ \\
\hline Secondary + & 1.14 & $(0.81,1.61)$ & 0.79 & $(0.47,1.33)$ & 0.67 & $(0.52,0.88)$ & 1.63 & $(1.18,2.24)$ & 0.86 & $(0.64,1.17)$ \\
\hline \multicolumn{11}{|l|}{ Employment } \\
\hline Unemployed (reference) & 1.00 & & 1.00 & & 1.00 & & 1.00 & & 1.00 & \\
\hline Employed & 0.77 & $(0.63,0.95)$ & 0.96 & $(0.70,1.31)$ & 1.04 & $(0.88,1.22)$ & 1.35 & $(1.12,1.62)$ & 0.86 & $(0.73,1.03)$ \\
\hline \multicolumn{11}{|l|}{ Wealth index } \\
\hline Poorest (reference) & 1.00 & & 1.00 & & 1.00 & & 1.00 & & 1.00 & \\
\hline Second quintile & 1.22 & $(0.90,1.66)$ & 0.8 & $(0.54,1.20)$ & 0.75 & $(0.59,0.94)$ & 1.65 & $(1.19,2.27)$ & 1.04 & $(0.83,1.32)$ \\
\hline Third quintile & 1.26 & $(0.93,1.71)$ & 0.68 & $(0.45,1.05)$ & 0.7 & $(0.55,0.89)$ & 2.94 & $(2.15,4.02)$ & 0.71 & $(0.55,0.91)$ \\
\hline Fourth quintile & 1 & $(0.71,1.41)$ & 0.61 & $(0.38,0.97)$ & 0.72 & $(0.56,0.93)$ & 4.63 & $(3.33,6.45)$ & 0.54 & $(0.41,0.71)$ \\
\hline Richest & 0.82 & $(0.55,1.22)$ & 0.42 & $(0.24,0.74)$ & 0.74 & $(0.56,0.99)$ & 9.43 & $(6.57,13.53)$ & 0.23 & $(0.16,0.33)$ \\
\hline \multicolumn{11}{|l|}{ Adults in household } \\
\hline One (reference) & 1.00 & & 1.00 & & 1.00 & & 1.00 & & 1.00 & \\
\hline Two adults & 0.98 & $(0.79,1.23)$ & 1 & $(0.73,1.37)$ & 1.02 & $(0.86,1.20)$ & 1.01 & $(0.84,1.22)$ & 0.95 & $(0.79,1.13)$ \\
\hline Three or more adults & 0.96 & $(0.73,1.27)$ & 0.51 & $(0.33,0.80)$ & 1.41 & $(1.15,1.74)$ & 1.07 & $(0.83,1.37)$ & 0.66 & $(0.52,0.84)$ \\
\hline Constant & 0.11 & $(0.08,0.16)$ & 0.02 & $(0.01,0.03)$ & 1.22 & $(0.95,1.57)$ & 0.03 & $(0.02,0.05)$ & 0.63 & $(0.48,0.84)$ \\
\hline
\end{tabular}

and the harmful use of alcohol - that would deliver the greatest benefit in reducing population level risks in a cost-effective manner [20].

A recent NCD prevention policy review for Kenya revealed a fairly better formulated tobacco control policy addressing all WHO "best buy" interventions such as tax increases, bans on tobacco advertising, and warnings on the dangers of tobacco; a weak alcoholic drinks control act (ADCA) addressing some of the "best buy" interventions including taxation and restriction to alcohol access; and a deficient food and nutrition policy not adequately addressing "best buy" interventions for unhealthy diet [21]. Although physical activity policies are not given priority, no cluster emerged with physical inactivity as the main risk factor because most people are active through work and travel other than recreation [22].

For injuries, $62 \%$ of the population was classified into two high risk injury clusters referred to as the defiant (36\%) for not using seatbelts and jaywalkers (26\%) because of inappropriate road crossing. The remaining two clusters which were low risk included helmet users (33\%) and the compliant (5\%) who used belts 
Table 5 Distribution of injury risk factors by clusters

\begin{tabular}{|c|c|c|c|c|c|c|}
\hline SN & NCD Risk Variables & Cluster 1 & Cluster 2 & Cluster 3 & Cluster 4 & Total \\
\hline 1 & Didn't use seatbelt & 25.1 & 0.0 & 100 & 0.0 & 55.3 \\
\hline 2 & Didn't use helmet & 0.0 & 100 & 100 & 100 & 67.1 \\
\hline 3 & Involved in traffic crash & 5.6 & 6.0 & 4.5 & 6.4 & 5.3 \\
\hline 4 & Had injury & 9.3 & 12.0 & 12.2 & 16.7 & 11.4 \\
\hline 5 & Inappropriate road crossing & 76.5 & 100 & 91.4 & 0.0 & 84.1 \\
\hline 6 & Driving under influence of alcohol & 2.9 & 2.7 & 3.0 & 2.5 & 2.9 \\
\hline 7 & Was a passenger of drunk driver & 9.8 & 12.6 & 12.9 & 18.7 & 12.1 \\
\hline 8 & Involved in violence & 2.9 & 3.9 & 4.6 & 5.9 & 3.9 \\
\hline \multirow[t]{4}{*}{9} & Substance use & 6.9 & 5.7 & 6.4 & 5.9 & 6.4 \\
\hline & Cluster size & 1310 & 1019 & 1449 & 203 & 3981 \\
\hline & $\%$ of total & 33.0 & 26.0 & 36.0 & 5.0 & 100 \\
\hline & Suggested cluster name & Helmet users & Jaywalkers & The defiant & The compliant & \\
\hline
\end{tabular}

$N C D=$ Non-Communicable diseases; the clusters are groups of study participants with similar pattern of NCD risk factors; All the values for risk factors are percentages

consistently and crossed roads appropriately. A recent survey conducted in five regional referral hospitals in Kenya showed that road traffic accidents were the most common injury among patients admitted in the emergency department and this is consistent with the clustering of risk factors at population level in this study [23]. Two other studies in Kenya have also revealed that among road traffic injuries, passengers in public transport vehicles followed by pedestrians were most involved [24, 25]. These accidents could have occurred because of non-compliance with belt use or jaywalking (inappropriate road crossing) reported in our study.

Identification of demographic characteristics associated with NCD risk clusters and the injury risk clusters is essential for programming successful primary preventive measures. We therefore profiled the NCD and injury risk clusters to inform differentiated prevention and care services. The factors that stood out as independent predictors of NCD risk clusters were; age, gender, education, wealth and living arrangements. Hypertension, harmful use of alcohol or salt and tobacco smoking, and obesity increased with age while fat consumption reduced with age. Men were more likely to be hypertensive, harmful users and fat lovers, while women were more likely to be obese.

The gender and age association with NCD risk has been well established before in Kenya [14]. An interesting finding in relation to age is the high consumption of fats by younger people. This may be explained by growing westernization of diet that young people are quickly adapting to and it is often observed in the early phase of nutrition transition characterized by a high consumption of fats, sweeteners and inadequate fruit intake as in the fat lovers' cluster that was dominated by young people this study [19]. Shopping in supermarkets in Kenya is increasing and making in-roads beyond the richer consumers to lower-income groups in smaller towns with up to $56 \%$ of the customers in supermarkets reported to be from low income groups [26]. This has implications on the food choices of young people.

Education has an additional benefit in reducing NCD risk as illustrated in our study by the increase in the proportion of those in the hopeful cluster with education, however obesity increased with education. Likewise, wealth was associated with a reduction in NCD risk due to less harmful use of alcohol, salt and reduced tobacco smoking, less fat consumption but obesity also increased with wealth. Education influences health behaviors and attitudes and consequently, lifestyle through exposure to relevant health information and comprehension of the information [27]. The increase in obesity by education and wealth may be a result of increased exposure to advertisements by the food industry that has the potential to change food choices among the educated and wealthy who can afford to buy these foods.

It was also interesting to note that when three or more people shared a household, they were less likely to engage in high consumption of salt, fat, harmful consumption of alcohol and tobacco smoking. This may be largely attributed to a social audit by other household members checking on each other's lifestyle and eating habits. For the same reason, the married are less likely to smoke or consume alcohol. Personal social networks have been reported to be associated with compliance to good health promoting behaviors [28].

Surprisingly no difference in NCD risk profile was observed between rural and urban residents contrary to studies showing that urbanicity is associated several NCD risk factors in India and Philippines [29, 30]. A recent study in rural Uganda also showed that increasing urbanicity was associated with an increase in lifestyle risk factors particularly physical inactivity, low fruit and vegetable consumption and high body mass index [31]. 
Table 6 Clusters of injury risk factors by background variables

\begin{tabular}{|c|c|c|c|c|c|c|}
\hline SN & NCD Risk Variables & Helmet users & Jaywalkers & The defiant & The compliant & $\begin{array}{l}\text { Chi-square } \\
\text { (P-value) }\end{array}$ \\
\hline \multirow[t]{5}{*}{1} & Age & & & & & \\
\hline & $18-29$ & 30.9 & 32.2 & 36.3 & 37.4 & \multirow{4}{*}{$\begin{array}{l}\text { Chi }=16.6 \\
P=0.055\end{array}$} \\
\hline & $30-44$ & 39.2 & 40.7 & 36.2 & 38.4 & \\
\hline & $45-59$ & 20.0 & 19.3 & 18.2 & 15.3 & \\
\hline & $60-69$ & 9.9 & 7.8 & 9.3 & 8.9 & \\
\hline \multirow[t]{3}{*}{2} & Sex & & & & & \\
\hline & Female & 54.4 & 58.6 & 65.1 & 58.1 & \multirow{2}{*}{$\begin{array}{l}\text { Chi }=33.6 \\
P=0.000\end{array}$} \\
\hline & Male & 45.7 & 41.4 & 34.9 & 41.9 & \\
\hline \multirow[t]{3}{*}{3} & Residence & & & & & \\
\hline & Rural & 54.1 & 49.2 & 52.3 & 43.8 & \multirow{2}{*}{$\begin{array}{l}\text { Chi }=10.7 \\
P=0.013\end{array}$} \\
\hline & Urban & 46.0 & 50.8 & 47.7 & 56.2 & \\
\hline \multirow[t]{5}{*}{4} & Education & & & & & \\
\hline & No schooling & 17.1 & 9.3 & 26.4 & 6.4 & \multirow{4}{*}{$\begin{array}{l}\text { Chi }=155.6 \\
P=0.000\end{array}$} \\
\hline & Primary incomplete & 24.7 & 25.1 & 24.0 & 26.1 & \\
\hline & Primary complete & 31.0 & 34.0 & 28.3 & 30.1 & \\
\hline & Secondary+ & 27.2 & 31.6 & 21.3 & 37.4 & \\
\hline \multirow[t]{3}{*}{5} & Employment & & & & & \\
\hline & Employed & 38.5 & 37.6 & 46.5 & 34.0 & \multirow{2}{*}{$\begin{array}{l}\text { Chi }=30.7 \\
P=0.000\end{array}$} \\
\hline & Unemployed & 61.5 & 62.4 & 53.5 & 66.0 & \\
\hline \multirow[t]{6}{*}{6} & Wealth index & & & & & \\
\hline & Poorest & 20.4 & 14.0 & 27.7 & 12.3 & \multirow{5}{*}{$\begin{array}{l}\text { Chi }= \\
P=0.000\end{array}$} \\
\hline & Second & 18.4 & 22.0 & 19.6 & 22.2 & \\
\hline & Third & 19.6 & 19.6 & 19.2 & 16.8 & \\
\hline & Fourth & 20.2 & 20.9 & 19.5 & 20.7 & \\
\hline & Richest & 21.5 & 23.5 & 14.0 & 28.1 & \\
\hline \multirow[t]{3}{*}{7} & Marital status & & & & & \\
\hline & Not in Union & 29.9 & 31.9 & 32.0 & 35.0 & \multirow{2}{*}{$\begin{array}{l}\text { Chi }=108.1 \\
P=0.383\end{array}$} \\
\hline & Union & 70.2 & 68.1 & 68.0 & 65.0 & \\
\hline
\end{tabular}

$N C D=$ Non-Communicable diseases; Values in the clusters are percentages

The common feature among these studies was the use of a multi-component scale to accurately define urbanicity even among villages considered to be rural and they found marked variation in levels of urbanicity across the villages, largely attributable to differences in economic activity, civil infrastructure, and availability of educational and healthcare services. Studies that loosely defined villages as urban or rural based on demarcation by national statistical bureaus as in this study have found no difference in NCD risk profiles among rural and urban populations, especially for hypertension $[17,18]$. This suggests that even within rural populations social inequalities may exist which are often missed by the statistical bureaus because their classification of communities into rural and urban centers may not capture all the urbanicity scale components.
Regarding injuries, age, education and wealth improved compliant behaviors such as use of belts and helmets, and reduced defiant behaviors meaning as people get older or more educated or wealthier they become more responsible and tend to follow injury risk prevention measures. Education mediates comprehension of information such as written traffic rules or through an early exposure to a teaching curriculum in schools that includes traffic rules. It is worthwhile to mention that on the contrary jaywalking did not reduce with education, age, or wealth, but was instead seen to increase. A systematic review of literature on road traffic injuries in Kenya revealed that road traffic injuries have increased by four fold in three decades and up to $75 \%$ of the causalities are young adults aged $18-44$ years, $80 \%$ of deaths are accounted for by pedestrians and passengers [25]. 
Table 7 Predictors of the injury clusters

\begin{tabular}{|c|c|c|c|c|c|c|c|c|}
\hline & \multicolumn{2}{|c|}{ Helmet users } & \multicolumn{2}{|c|}{ Jaywalkers } & \multicolumn{2}{|c|}{ The defiant } & \multicolumn{2}{|c|}{ The compliant } \\
\hline & $\mathrm{OR}$ & $(95 \% \mathrm{Cl})$ & $\mathrm{OR}$ & $(95 \% \mathrm{Cl})$ & $\mathrm{OR}$ & $(95 \% \mathrm{Cl})$ & $\mathrm{OR}$ & $(95 \% \mathrm{Cl})$ \\
\hline \multicolumn{9}{|l|}{ Age } \\
\hline 18-29 (reference) & 1.00 & & 1.00 & & 1.00 & & 1.00 & \\
\hline $30-44$ & 1.14 & $(0.96,1.34)$ & 1.22 & $(1.02,1.46)$ & 0.76 & $(0.65,0.90)$ & 0.92 & $(0.65,1.30)$ \\
\hline $45-59$ & 1.23 & $(1.00,1.50)$ & 1.25 & $(1.01,1.56)$ & 0.71 & $(0.58,0.87)$ & 0.79 & $(0.50,1.23)$ \\
\hline $60-69$ & 1.31 & $(1.01,1.70)$ & 1.19 & $(0.89,1.61)$ & 0.64 & $(0.50,0.83)$ & 1.23 & $(0.71,2.15)$ \\
\hline \multicolumn{9}{|l|}{ Sex } \\
\hline Female (reference) & 1.00 & & 1.00 & & 1.00 & & 1.00 & \\
\hline Male & 1.38 & $(1.20,1.59)$ & 0.93 & $(0.80,1.09)$ & 0.79 & $(0.68,0.92)$ & 0.89 & $(0.66,1.21)$ \\
\hline \multicolumn{9}{|l|}{ Marital Status } \\
\hline Not in union (reference) & 1.00 & & 1.00 & & 1.00 & & 1.00 & \\
\hline In union & 1.10 & $(0.93,1.29)$ & 0.94 & $(0.79,1.12)$ & 0.95 & $(0.81,1.11)$ & 1.02 & $(0.73,1.42)$ \\
\hline \multicolumn{9}{|l|}{ Residence } \\
\hline Rural (reference) & 1.00 & & 1.00 & & 1.00 & & 1.00 & \\
\hline Urban & 0.72 & $(0.62,0.85)$ & 0.95 & $(0.80,1.12)$ & 1.40 & $(1.19,1.64)$ & 1.14 & $(0.81,1.61)$ \\
\hline \multicolumn{9}{|l|}{ Education } \\
\hline No schooling (reference) & 1.00 & & 1.00 & & 1.00 & & 1.00 & \\
\hline Primary incomplete & 1.05 & $(0.84,1.32)$ & 2.11 & $(1.60,2.79)$ & 0.52 & $(0.42,0.64)$ & 2.97 & $(1.55,5.69)$ \\
\hline Primary complete & 1.04 & $(0.82,1.31)$ & 2.32 & $(1.75,3.07)$ & 0.49 & $(0.39,0.61)$ & 2.68 & $(1.38,5.20)$ \\
\hline Secondary + & 0.94 & $(0.73,1.22)$ & 2.51 & $(1.85,3.39)$ & 0.46 & $(0.36,0.59)$ & 3.75 & $(1.88,7.47)$ \\
\hline \multicolumn{9}{|l|}{ Employment } \\
\hline Unemployed (reference) & 1.00 & & 1.00 & & 1.00 & & 1.00 & \\
\hline Employed & 1.00 & $(0.86,1.17)$ & 0.98 & $(0.83,1.15)$ & 0.99 & $(0.85,1.15)$ & 1.13 & $(0.81,1.58)$ \\
\hline \multicolumn{9}{|l|}{ Wealth Index } \\
\hline Poorest (reference) & 1.00 & & 1.00 & & 1.00 & & 1.00 & \\
\hline Second & 0.93 & $(0.74,1.17)$ & 1.41 & $(1.09,1.82)$ & 0.79 & $(0.63,0.98)$ & 1.38 & $(0.82,2.34)$ \\
\hline Third & 1.12 & $(0.89,1.42)$ & 1.25 & $(0.96,1.62)$ & 0.78 & $(0.62,0.97)$ & 1.01 & $(0.57,1.76)$ \\
\hline Fourth & 1.24 & $(0.97,1.59)$ & 1.31 & $(0.99,1.73)$ & 0.67 & $(0.53,0.85)$ & 1.06 & $(0.59,1.88)$ \\
\hline Richest & 1.59 & $(1.20,2.11)$ & 1.52 & $(1.12,2.06)$ & 0.43 & $(0.32,0.56)$ & 1.28 & $(0.69,2.36)$ \\
\hline \multicolumn{9}{|l|}{ Adults in household } \\
\hline One (reference & 1.00 & & 1.00 & & 1.00 & & 1.00 & \\
\hline Two & 0.97 & $(0.83,1.14)$ & 1.10 & $(0.93,1.31)$ & 1.01 & $(0.86,1.18)$ & 0.76 & $(0.54,1.06)$ \\
\hline Three or more & 0.98 & $(0.80,1.21)$ & 1.03 & $(0.83,1.29)$ & 1.01 & $(0.83,1.24)$ & 0.92 & $(0.60,1.40)$ \\
\hline Constant & 0.36 & $(0.29,0.47)$ & 0.12 & $(0.09,0.16)$ & 1.69 & $(1.34,2.14)$ & 0.02 & $(0.01,0.04)$ \\
\hline
\end{tabular}

The traffic rules and enforcement seem to pay little attention to pedestrians. Most times the pedestrians break traffic rules and are not apprehended but instead treated as the victim of accidents. Public awareness about road safety especially for passengers and pedestrians is limited, thus the high risk of injuries among these groups.

The findings of this study have important implication for policy, practice and research. The identified clusters can guide where NCD policies and strategies need to focus. The resulting clusters would also be useful in the planning, implementation and evaluation of segmented approach to the prevention and control of NCDs. Similarly, future research projects could use these clusters to further explore the various characteristics associated with NCD profiles of the population of Kenya.

\section{Strengths and limitations}

A major strength of this paper is the large sample size representative of the Kenyan population and this has provided an opportunity to investigate NCD and injury risk factors at national level. Secondly, the cluster analytical approach used in this paper identified important 
clusters of adult Kenyans with specific NCD and injury risk profiles for potential development of differentiated population-based interventions. However the main limitation of this cluster analytical approach is that it does not take into consideration the concurrency of risk factors, thus excludes important messages for those with multiple risk factors. Self-reported behavioural risk factors such as dietary intake and harmful use of alcohol are prone to bias, as participants may not accurately estimate quantities consumed or could purposefully conceal information for social desirability. We also excluded from the analysis individuals with incomplete records with respect to the key NCD and injury variables, which may have affected our analysis approach.

\section{Conclusions}

In conclusion, this nationally representative survey reveals interesting patterns of NCD and injury risk clusters generated through K-medians cluster analysis which is a popular form of cluster analysis due to its simplicity of implementation, ability to partition large data sets, and ease in interpretation of its cluster solution and tolerance of outliers [32,33]. This analysis has provided a holistic view of patterns of risk at population level for decision-makers to target populations with appropriate interventions. The main population groups to be prioritized for targeted NCD prevention interventions include; those with unhealthy diet (young fat lovers), the obese and hypertensive (older, wealthy and educated, men) and harmful users of alcohol, salt and tobacco (unmarried, older, living alone). When designing NCD preventive interventions rural populations should also be considered. Since Kenya is in the early stage of epidemiological transition, there is a window of opportunity to implement primordial NCD prevention measures to curtail the growing NCD epidemic. There is need for a multi-sectoral action to strengthen policies and implementation of programs with a focus on tackling unhealthy diet, prevention and management of hypertension and obesity. Strengthening the existing policies for tobacco and alcohol control to further reduce the current frequency of consumption and the experiences of developing these policies should inform the design of robust nutrition policies.

For injuries, there is need to design targeted messaging for road safety measures particularly for young, poor and uneducated people. Clear guidelines on safety measures for pedestrians and general public awareness on traffic guidelines for pedestrians are needed. Lastly, enhanced enforcement of traffic laws for pedestrians and passengers in public transport will be crucial in reducing road traffic injuries.

\section{Abbreviations}

ADCA: Alcoholic Drinks Control Act; APHRC: African Population and Health Research Center; CVD: Cardiovascualr diseases; MoH: Ministry of Health, Kenya; NASSEP V: National sample surveys and evaluation programme;
NCD: Non-communicable diseases; PDA: Personal digital assistant; SSA: SubSaharan Africa; STEPS: The WHO STEPwise approach to Surveillance of noncommunicable diseases; WHO: World Health Organization

\section{Acknowledgements}

We would like to thank all the individuals and organizations that provided technical support for the design and implementation of the main survey. Funding for the main survey was provided by World Bank, World Health Organisation $(\mathrm{WHO})$, Astrazeneca and the Ministry of Health $(\mathrm{MOH})$ and the Center for Diseases Control (CDC). Authors are also grateful to the data collection and analysis team led by the $\mathrm{MOH}, \mathrm{WHO}$ and Kenya National Bureau of Statistics (KNBS), Kenya Medical Research Institute (KEMRI) and African Institute for Health and Development (AlHD).

\section{Funding}

The writing of this paper and publication cost was made possible through the generous funding made to African Population and Health Research Center (APHRC), from International Development Research Center (IDRC) (grant \# 107209-001). FMW is funded for his PhD research by a Global Health Support Program Scholarship of the University Medical Center, Utrecht University, the Netherlands.

\section{Availability for data and materials}

Data and materials are available by writing to Gladwell Gathecagladwellgathecha@gmail.com.

\section{About this supplement}

This article has been published as part of BMC Public Health Volume 18 Supplement 3, 2018: Special issue from national survey on NCD risk factors in Kenya. The full contents of the supplement are available online at https:// bmcpublichealth.biomedcentral.com/articles/supplements/volume-18supplement-3.

\section{Authors' contributions}

TNH and FMW conceptualized the study, drafted the plan of analysis, conducted the analysis and led the writing of the manuscript. MKM, SFM, GA and CK contributed to the design of study, and writing of the manuscript. All authors have read and approved the final manuscript.

\section{Ethics approval and consent to participate}

Kenya Medical Research Institute's Ethics Review Committee had reviewed and approved the study (SSC No. 2607). Study respondents were provided with information in a language easy to understand, and an opportunity to determine if they wanted to participate or not.

Consent for publication

Not applicable.

\section{Competing interests}

The authors declare that they have no competing interest.

\section{Publisher's Note}

Springer Nature remains neutral with regard to jurisdictional claims in published maps and institutional affiliations.

\section{Author details}

${ }^{1}$ African Population and Health Research Center (APHRC), 2nd Floor APHRC Campus, Manga Close Off Kirawa Road, P.O. Box 10787, Kitisuru, Nairobi GPO 00100, Kenya. ${ }^{2}$ Julius Global Health, Julius Center for Health Sciences and Primary Care, University Medical Center, Utrecht University, Utrecht, The Netherlands. ${ }^{3}$ Division of Health Sciences, Warwick Medical School, University of Warwick, Coventry, UK. ${ }^{4}$ Non-communicable Diseases Unit, University of Melbourne, Melbourne, Australia.

Published: 7 November 2018

\section{References}

1. World Health Organization. Global status report on noncommunicable diseases 2014. Geneva: World Health Organization; 2014.

2. World Health Organization. Noncommunicable Diseases Country Profiles; 2014. p. 2014. 
3. Lopez AD, Mathers CD, Ezzati M, Jamison DT, Murray CJ. Global and regional burden of disease and risk factors, 2001: systematic analysis of population health data. Lancet. 2006;367(9524):1747-57.

4. Boutayeb A. The double burden of communicable and non-communicable diseases in developing countries. Trans R Soc Trop Med Hyg. 2006;100(3):191-9.

5. Murray C, Lopez AD. Summary: the global burden of disease: a comprehensive assessment of mortality and disability from diseases, injuries, and risk factors in 1990 and projected to 2020. Geneva and Boston: World Health Organization and Harvard School of Public Health; 1996.

6. Lozano R, Naghavi M, Foreman K, Lim S, Shibuya K, Aboyans V, et al. Global and regional mortality from 235 causes of death for 20 age groups in 1990 and 2010: a systematic analysis for the global burden of disease study 2010. Lancet. 2013;380(9859):2095-128.

7. Kontis V, Mathers CD, Rehm J, Stevens GA, Shield KD, Bonita R, et al. Contribution of six risk factors to achieving the $25 \times 25$ non-communicable disease mortality reduction target: a modelling study. Lancet. 2014;384(9941):427-37.

8. Khatib O. Noncommunicable diseases: risk factors and regional strategies for prevention and care. East Mediterr Health J. 2004;10(6):778-88.

9. World Health Organization. World Health Organization STEPwise approach to chronic disease risk factor surveillance (STEPS) instrument. Geneva: World health organization; 2007.

10. World Health Organization. Global recommendations on physical activity for health. Switzerland: World Health Organization; 2010.

11. World Health Organization. Guideline: sodium intake for adults and children. Geneva: WHO; 2012

12. World Health Organization. Healthy Diet: WHO; 2015 [cited 2017 April 15]. Available from: http://www.who.int/en/news-room/fact-sheets/detail/ healthy-diet

13. World Health Organization. BMI Classification: WHO; 2018 [cited 2017 April 25]. Available from: http://www.who.int/gho/ncd/risk_factors/bmi_text/en/.

14. Kaduka LU, Kombe Y, Kenya E, Kuria E, Bore JK, Bukania ZN, et al. Prevalence of metabolic syndrome among an urban population in Kenya. Diabetes Care. 2012;35(4):887-93.

15. Christensen DL, Friis H, Mwaniki D, Kilonzo B, Tetens I, Boit M, et al. Prevalence of glucose intolerance and associated risk factors in rural and urban populations of different ethnic groups in Kenya. Diabetes Res Clin Pract. 2009;84(3):303-10.

16. Van de Vijver SJ, Oti SO, Agyemang C, Gomez GB, Kyobutungi C. Prevalence, awareness, treatment and control of hypertension among slum dwellers in Nairobi Kenya. J hypertens. 2013;31(5):1018-24.

17. Guwatudde D, Mutungi G, Wesonga R, Kajjura R, Kasule H, Muwonge J, et al. The epidemiology of hypertension in Uganda: findings from the national non-communicable diseases risk factor survey. PLoS One. 2015;10(9): e0138991.

18. Kavishe B, Biraro S, Baisley K, Vanobberghen F, Kapiga S, Munderi P, et al. High prevalence of hypertension and of risk factors for non-communicable diseases (NCDs): a population based cross-sectional survey of NCDS and HIV infection in northwestern Tanzania and southern Uganda. BMC Med. 2015;13(1):126.

19. Popkin BM. The nutrition transition and its health implications in lowerincome countries. Public Health Nutr. 1998;1(1):5-21.

20. Organization $\mathrm{WH}$. Global action plan for the prevention and control of noncommunicable diseases 2013-2020. 2013.

21. Juma P, Mohamed S, Kyobutungi $C$. Analysis of non-communicable disease prevention policies in Kenya. 2017.

22. Ayah R, Joshi MD, Wanjiru R, Njau EK, Otieno CF, Njeru EK, et al. A population-based survey of prevalence of diabetes and correlates in an urban slum community in Nairobi, Kenya. BMC Public Health. 2013;13(1):371.

23. Botchey IM, Hung YW, Bachani AM, Paruk F, Mehmood A, Saidi H, et al. Epidemiology and outcomes of injuries in Kenya: a multisite surveillance study. Surgery. 2017 162(6S):S45-S53.

24. Odero W, Kibosia J. Incidence and characteristics of injuries in Eldoret, Kenya. East Afr Med J. 1995;72(11):706-10.

25. Odero W, Khayesi M, Heda P. Road traffic injuries in Kenya: magnitude, causes and status of intervention. Inj Control Saf Promot. 2003;10(1-2):53-61.

26. Neven D, Reardon T, Chege J, Wang H. Supermarkets and consumers in Africa: the case of Nairobi, Kenya. J Int Food Agribusiness Marketing. 2006; 18(1-2):103-23.

27. Scuteri A, Vuga M, Najjar S, Mehta V, Everson-Rose S, Sutton-Tyrrell K, et al. Education eclipses ethnicity in predicting the development of the metabolic syndrome in different ethnic groups in midlife: the study of Women's health across the nation (SWAN). Diabet Med. 2008;25(12):1390-9.
28. Marquez B, Elder JP, Arredondo EM, Madanat H, Ji M, Ayala GX. Social network characteristics associated with health promoting behaviors among Latinos. Health Psychol. 2014;33(6):544.

29. Allender $S$, Lacey B, Webster $P$, Rayner $M$, Deepa $M$, Scarborough $P$, et al. Level of urbanization and noncommunicable disease risk factors in Tamil Nadu, India. Bull World Health Organ. 2010;88(4):297-304.

30. Allender S, Wickramasinghe K, Goldacre M, Matthews D, Katulanda P. Quantifying urbanization as a risk factor for noncommunicable disease. J Urban Health. 2011:88(5):906.

31. Riha J, Karabarinde A, Ssenyomo G, Allender S, Asiki G, Kamali A, et al. Urbanicity and lifestyle risk factors for cardiometabolic diseases in rural Uganda: a cross-sectional study. PLoS Med. 2014;11(7):e1001683.

32. Bailey KD. Sage Publications i: Typologies and Taxonomies: An Introduction to Classification Techniques. SAGE Publications; 1994.

33. Gan G, Ma C, Wu J. Data clustering: theory, algorithms, and applications. Society for Industrial and Applied Mathematics; 2007. 